\title{
O CONCEITO JURÍDICO DA FRATERNIDADE IMPRESSO NA FUNÇÃO SOCIAL DOS CONTRATOS
}

\section{IL CONCETTO GIURIDICO DELLA FRATERNITÀ STAMPATO NELLA FUNZIONE SOCIALE DEI CONTRATTI}

\author{
${ }^{1}$ Wagner Felipe Macedo Vilaça \\ ${ }^{2}$ Simone Reissinger
}

\section{RESUMO}

A Revolução Francesa proclamou a sua célebre tríade: fraternidade, igualde e liberdade. Durante muito tempo o direito preocupou-se em normatizar somente direitos relativos à liberdade e à igualdade. Hoje, sobre as bases do Estado Democrático de Direito, em que a dignidade da pessoa humana é um dos alicerces do sistema, surge a necessidade de reaver o conceito da fraternidade perdido no tempo. Isto porque a sociedade proclama a necessidade de respeitar os direitos individuais de liberdade, assegurando a todos o mínimo existencial. Acredita-se que justamente a fraternidade pode exercer este papel, materializando-se através de institutos jurídicos, como por exemplo, a função social dos contratos. Trata-se de uma pesquisa que envolve Direito Civil, Direito Constitucional e História do Direito. Portanto, foi desenvolvida uma análise bibliográfica do entrelaçamento dos conceitos-chave fraternidade, função social dos contratos e dignidade da pessoa humana -, ao Estado Democrático de Direito. O objetivo deste artigo é verificar a possibilidade de, no princípio da função social dos contratos, localizar um emprego jurídico da fraternidade. Sendo, ao final, possível afirmar que não somente $\mathrm{o}$ instituto da função social dos contratos, mas também outros podem ser considerados inspirados no uso jurídico da fraternidade.

Palavras-chave: Fraternidade, Função social dos contratos, Dignidade da pessoa humana, Estado democrático de direito

\section{RÉSUMÉ}

La Rivoluzione Francese ha proclamato la sua celebre triade: fraternità, uguaglianza e libertà. Da molto tempo, il diritto si è preoccupato di regolare soltanto i diritti concernenti alla libertà e alluguaglianza. Oggi, sulle basi dello Stato Democratico di Diritto, in cui la dignità della persona umana è uno dei fondamenti del sistema, sorge la necessità di recuperare il concetto della fraternità perso nel tempo. Questo perché, la società proclama la necessità di rispettare i diritti individuali di libertà, assicurando ai tutti il minimo esistenziale. Si ritiene che proprio la fraternità possa svolgere questa funzione, si materializzando attraverso degli istituti giuridici, ad esempio, la funzione sociale dei contratti. Si tratta di una ricerca che coinvolge, Diritto Civile, Diritto Costituzionale e Storia del Diritto. Pertanto, sarà sviluppata unanalisi della letteratura dinterleaving dei concetti-chiave la fraternità, la funzione sociale dei contratti e della dignità della persona umana -, allo Stato Democratico di Diritti. Pertanto, L obiettivo di questarticolo è verificare la possibilità di, nel principio della funzione sociale dei contratti, trovare un uso giuridico della fraternità. Al fine, sarà possibile dire che non solo 1 istituto della funzione sociale dei contratti, ma altri tanti, possono essere considerati ispirati nelluso giuridico della fraternità.

Mots-clés: Fraternità, Funzione sociale dei contratti, Dignità della persona umana, Stato democratico di diritti

\footnotetext{
${ }^{1}$ Mestrando em Direito pela Universidade Federal de Minas Gerais - UFMG, Minas Gerais, (Brasil) Email: tutortreinamneto@gmail.com

${ }^{2}$ Doutora em Direito pela Pontifícia Universidade Católica de Minas Gerais - PUC, Minas Gerais, (Brasil).
} 


\section{INTRODUÇÃ̃O}

Este artigo é resultado das considerações finais obtidas a partir do projeto de pesquisa (PROBIC) financiado pela instituição de Pesquisa FAPEMIG, no ano de 2013, bem como da continuidade dos estudos em curso de Mestrado. A justificativa em pesquisar sobre o tema surge da necessidade de se fortalecer a função social dos contratos demonstrando a fraternidade como uma possível fonte jurídica de sua construção reafirmando, assim, as bases do Estado Democrático de Direito e promovendo a dignidade da pessoa humana. Ademais, trazendo à fraternidade um cunho jurídico, a construção do Estado estaria completa, se analisada sobre os ideais revolucionários franceses.

Constitui-se como objetivo principal a verificação da interpretação da fraternidade com um uso jurídico a partir da função social dos contratos. E, para tanto, necessário uma análise dos conceitos de função social dos contratos, fraternidade e dignidade da pessoa humana, para que, ao final, todos estes se entrelacem ao Estado Democrático de Direito.

Pretendeu-se alcançar os objetivos desenhados através de uma pesquisa críticobibliográfica.

\section{FUNÇÃO SOCIAL DOS CONTRATOS}

O Código Civil Brasileiro de 2002 tem um papel muito importante para o período em que foi promulgado e pode ser considerado como um avanço necessário para a conjuntura política/econômica do Brasil do final do século XX e início do século XXI.

Isso porque a Constituição brasileira de 1988 elegeu o Estado Democrático de Direito como modelo estatal.

Neste modelo estatal há uma preocupação com o respeito do ser humano e com a sua dignidade (o que leva à conclusão que não somente a grande massa importa, mas também as minorias), e mais que isso, pretende garantir a atuação efetiva do cidadão na política estatal.

A preocupação política, no Estado Democrático de Direito, transcende a figura individual, e até mesmo a figura social, para alcançar valores que se espelham na preocupação 
com as futuras gerações, surgindo, a partir daí, legislações que visam resguardar o meio ambiente, a defesa do consumidor, dentre outros. Estes são os chamados direitos difusos.

Assim, o Código Civil que sucedesse ao de 1916 deveria preocupar-se com os novos valores trazidos pela Constituição de 1988; ou seja, as garantias fundamentais, ressaltando-se a dignidade da pessoa humana.

E para cumprir tal meta, o Código Civil de 2002 trabalha três paradigmas, quais sejam: operabilidade, eticidade e socialidade.

O paradigma da operabilidade pode ser resumido em duas chaves: a descomplicação do direito civil e a possibilidade de conferir ao magistrado a possiblidade de verificar as peculiaridades do caso concreto à aplicação da norma.

Pela eticidade percebe-se que o Código Civil, considerando a mudança de valores que pode ocorrer em uma determinada sociedade, elabora uma legislação mais flexível que atenderá aos anseios das pessoas as quais serve, sem que seja necessário, no entanto, uma mudança formal em seu texto.

O paradigma da socialidade está intimamente ligado com a busca do bem comum. E, portanto, a ideia de função social. Cada pessoa, individualmente considerada, em conjunto com a sociedade, deve buscar alcançar o bom convívio para todos. Assim, as pretensões individuais e coletivas poderão ser atendidas.

Neste ponto é necessário ter sedimentado, desde já, que a função social, como proposta do Novo Código, exige uma cooperação mútua entre os entes que compõem o Estado. Ao final deste artigo, tal entendimento será decisivo.

Tratados os paradigmas que norteiam a construção do Código Civil de 2002, passa-se a análise da função social dos contratos, pois agora se tem conhecimento das bases de tal instituto para o ordenamento jurídico brasileiro.

Primeiramente, é preciso estabelecer que o contrato é uma fonte de obrigações, assim como também são as leis. Entretanto, ao contrário das leis, tais deveres só existem para as partes que estão inseridas no universo contratual.

Aqui, cabe uma discussão. Quando uma lei não se enquadra no ordenamento jurídico existem meios de extirpá-la do sistema, através do controle de constitucionalidade. Isto se dá tanto em casos de ofensa ao texto da constituição quanto nos casos de ofensa a princípios norteadores também trazidos pela constituição. Mas, e se, uma cláusula, estipulada no contrato, for contra textos legais ou, até mesmo, princípios norteadores? É possível extirpá-la? E como deve ser tratada a eficácia das obrigações geradas por aquela cláusula? 
Diante do Código de 1916, principalmente de acordo com sua redação original, nada poderia ser feito, uma vez que a vontade contratual das partes (liberdade para contratar) deveria ser sempre respeitada.

O mesmo não acontece se aplicado o Código Civil de 2002. Isto porque a relação contratual estabelecida pode causar sérios prejuízos para as partes envolvidas, desrespeitando princípios constitutivos do Estado Democrático de Direito, como a dignidade da pessoa humana. Mesmo tratando-se de uma relação inter pars $^{l}$, o contrato pode refletir efeitos por toda a sociedade e daí a necessidade de se falar em função social dos contratos.

O professor Azevedo (2009) trata da restrição de contratar, imposta pelo Estado contemporâneo:

\begin{abstract}
Pelos contratos, os homens devem compreender-se e respeitar-se, para que encontrem um meio de entendimento e de negociação sadia de seus interesses e não um meio de opressão.

Para que esse espírito de fraternidade nos contratos se preserve, no âmbito do direito interno, têm os Estados modernos lançado mão de normas cogentes, interferindo nas contratações, comsua vontade soberana, para evitar lesões. (AZEVEDO, 2009, p. 18).
\end{abstract}

Como muito bem ressaltado pelo professor, os contratos refletem a vontade individual, mas dentro da perspectiva do Estado Democrático de Direito é inconcebível a ideia de não respeitar a dignidade da pessoa humana, bem como os fins aos quais o contrato se destina. É com base nisto que o direito brasileiro cria normas jurídicas para intervir, validar ou rever, de forma direta, a vontade das partes quando da celebração e execução contratual.

Em outras palavras, quando duas ou mais pessoas resolvem celebrar um contrato devem se preocupar não somente com a vontade particular que the deu origem (ou com a obrigação que visam estabelecer), mas também a sua função social, assim como consagrado no artigo 421 do Código Civil Brasileiro de 2002: “a liberdade de contratar será exercida em razão e nos limites da função social do contrato". Explica Azevedo:

\footnotetext{
O atual Código Civil não ficou à margem dessa indispensável necessidade de integrar o contrato na sociedade, como meio de realizar os fins sociais, pois determinou que a liberdade contratual (embora se refira equivocadamente a liberdade de contratar) deve ser "exercida em razão e nos limites da função social do contrato". Esse dispositivo (art. 421) alarga, ainda mais, a capacidade do juiz para proteger o mais fraco, na contratação, que, por exemplo, possa estar sofrendo pressão econômica ou os efeitos maléficos de cláusulas abusivas ou de publicidade enganosa (AZEVEDO, 2009, p.18).
}

\footnotetext{
${ }^{1}$ Entre as partes (tradução livre).
} 
O contrato, como matéria disciplinada pelo Código Civil de 2002, está condicionado aos paradigmas impostos por ele, ou seja, a operabilidade, eticidade e a socialidade. Desta forma, o instrumento contratual deve observar a função social.

A função social é, portanto, requisito de validade do contrato, sendo necessário um aprofundamento sobre este conceito.

Segundo Eduardo Sens do Santos (2003), em seu artigo intitulado "A função social dos contratos: elementos para uma conceituação”, são necessários dois requisitos para o cumprimento da função social nos contratos:

O primeiro deles é a adequada ponderação entre os três princípios fundamentais do direito contratual: a autonomia privada, a boa-fé objetiva e o equilíbrio contratual. Sem que estejam bem balanceados esses três princípios na relação contratual, efetivamente não se pode dizer que o contrato cumpriu sua função social, pois será uma mera imposição de uma parte sobre a outra, quando for desobedecido o principio da autonomia das partes; ou então será um contrato abusivo e desleal, quando faltar observância ao princípio da boa-fé objetiva; ou será um contrato injusto quando não se atentar para o princípio do equilíbrio contratual. (...) não basta apenas aquela relação de proporcionalidade entre os princípios. É necessário também que com o contrato se atinja ao bem comum. (SANTOS, 2003, p.109)

Portanto, para que a função social dos contratos seja atendida, necessário, primeiramente, a observância dos princípios da autonomia privada (livre vontade de contratar); da boa-fé objetiva (relação de lealdade entre as partes) e equilibrio contratual (cláusulas proporcionais para cada um dos contratantes). Tais princípios dizem respeito ao conteúdo formal dos contratos, mas não são suficientes para que se atenda à função social. É necessário, também, que o contrato vise atingir o bem comum, sendo este um elemento externo que transcende a figura dos contratantes para dizer respeito a todas as pessoas, ou seja, o bem comum engloba o sujeito (considerado individualmente), bem como o todo (sociedade em geral).

Já Christiane Hessler Furck (2008), em seu artigo intitulado "Conceito legal indeterminado: a função social do contrato e a função criadora do juiz”, cita Miguel Reale para explicar que a função social dos contratos é oriunda da função social da propriedade, devidamente amparada por texto constitucional ${ }^{2}$, e para ser atendida deve atender aos interesses da sociedade:

\begin{abstract}
O doutrinador alhures [Miguel Reale] afirma que "a função social da propriedade somente poderá ser alcançada através da extensão do principio aos contratos, tendo em vista que não geram efeitos às partes, mas sim à coletividade. Desta feita, o contrato terá cumprido a função social verificando-se que foi concluído em beneficio
\end{abstract}

\footnotetext{
${ }^{2}$ No artigo $5^{\circ}$ da Constituição brasileira de 1988 é estabelecido o direito à propriedade no inciso "XXII. é garantido o direito de propriedade", bem como a necessidade da propriedade atender sua função social "XXIII. a propriedade atenderá a sua função social".
} 
das partes e que estão ausentes quaisquer possibilidades de burla aos interesses da sociedade." (FURCK, 2008, p.97).

Também Furck (2008) cita Rosa Maria de Andrade Nery para dizer que a função social dos contratos é inspirada pelo princípio da solidariedade, visando alcançar uma sociedade justa e equilibrada. Ao final, conclui que a função social dos contratos é oriunda de princípios constitucionais e, não somente, da função social da propriedade. A partir desta conclusão trata do conceito de função social dos contratos:

\begin{abstract}
A função social do contrato é, antes de mais nada, instituto jurídico decorrente de ordem constitucional, que, nesse passo, consubstancia e coloca em prática preceitos constitucionais, como a dignidade da pessoa humana, solidariedade, livre iniciativa, função social da propriedade, razão pela qual se verifica que a interpretação casuística, conferida à função social do contrato, é maior que a exata definição que lhe possa conferir.

Nesse passo, de acordo comos ensinamentos de Nels on Nery Junior o contrato estará em conformidade com a função social quando se pautar pelos valores de solidariedade, justiça social, livre iniciativa, dignidade da pessoa humana e respeito aos valores ambientais. O contrato deverá atender não somente aos interesses individuais, mas deve servir-se de instrumento de convívio social e preservação dos interesses da coletividade (FURCK, 2008, p.97).
\end{abstract}

Como é possível perceber, a conceituação da função social dos contratos feita por Furck (2008) parece com aquela feita por Santos (2003). Ambos passam pela necessidade da observância dos princípios de dignidade da pessoa humana, bem como o respeito ao bem comum Assim como ambos os autores colocam os mesmos requisitos para que o contrato atenda à função social exigida por lei.

Como último ponto de análise sobre a função social dos contratos, importante o apontamento feito por Gomes que, "uma vez não observada sua função social, resulta o contrato atingido no plano de sua validade, porquanto a função, um dos elementos inderrogável - que o integra, teve um atributo - a sociabilidade - comprometido" (GOMES, 2003, p.11).

Portanto, a inobservância de um contrato quanto à sua função social é causa de nulidade. Tal explicação se faz importante para pensar na dimensão que é dada a tal instituto.

Como visto, a função social dos contratos visa equilibrar as relações sociais, intervindo na liberdade individual para contratar-se, devendo as partes, no ato da contratação, ter ciência que devem fazer o contrato em consonância com uma "solidariedade" entre os seres humanos (respeitando a dignidade da pessoa humana e o bem comum).

Assim, de acordo com o Código Civil de 2002, as partes devem preocupar-se, inclusive, com o não desrespeito da dignidade da pessoa humana e do bem estar da sociedade como um todo. 
Considerando, ainda, o Estado Democrático de Direito, percebe-se que a obrigação de zelar pela função social dos contratos é do Estado em consonância com a atuação de cada cidadão.

\section{UM CONCEITO JURÍDICO DE FRATERNIDADE}

Para a finalidade específica proposta neste artigo necessário, ainda, estabelecer um conceito de fraternidade, levando-se em consideração o paradigma do Estado Democrático de Direito, o que será feito a partir de então.

\subsection{A CONSTRUÇÃO DO CONCEITO}

O termo fraternidade alcança o auge de sua construção no Cristianismo, como comando necessário de tratamento entre as pessoas. Afinal, se todos são irmãos ${ }^{3}$, devem tratar- se com espírito de fraternidade.

Também é, no Cristianismo, a primeira vez que a fraternidade será utilizada sobre um prisma universal, vez que sua proposta é feita para todos aqueles que quiserem professar a fé cristã, mas independentemente de características físicas ou até mesmo da naturalidade que possuem.

A fraternidade cristã pode ser definida: "La fraternidad cristiana se funda últimamente en la fe, la cual nos da certeza de que somos realmente hijos del Padre celestial y hermanos de todos aquellos que comulgan con nosotros en la misma fe." ${ }^{4}$ (RATZINGER, 1962, p. 71).

Com a proposta universalizadora do Cristianismo, a fraternidade cristã passa a englobar todos aqueles que queiram fazer parte da mesma profissão de fé, dirigindo-se a mulheres, homens, livres e escravos, judeus, gregos... Enfim, a todos os povos. Tal fraternidade

\footnotetext{
${ }^{3}$ Segundo o Cristianismo, todos são irmãos porque os seres humanos são filhos de um único Deus, e, portanto, devem tratar-se com espírito de fraternidade. Tal ideia será melhor trabalhada ao longo deste tópico.

${ }^{4}$ A fraternidade cristã se funda ultimamente na fé, a qual nos dá certeza de que somos realmente filhos do pai celestial e irmãos de todos aqueles que comungam conosco na mesma fé. (tradução livre)
} 
se funda na fé de que somos filhos do mesmo Pai (Deus), irmãos de Jesus Cristo e, consequentemente, de todos que professam a mesma fé. Este entendimento gera consequências:

La unión con Cristo incluye la unión de los cristianos entre si, e implica, por tanto, una supresión de los limites naturales e históricos. Luego, por encima de los necesarios limites de los diversos estados y del orden jeráriquico, ha de reinar el “ehtos" de la igualdad y de la fraternidad. ${ }^{5}$ (RATZINGER, 1962, p. 77).

A fraternidade, segundo a doutrina cristã, está acima dos limites hierárquicos e da divisa dos Estados. Desta forma, estabelece uma igualdade entre os homens, ao passo que são todos iguais em substância e filhos do mesmo Pai. Segundo Ratzinger (1962), diante do Criador todas as diferenças ${ }^{6}$ dos seres humanos somem.

Ressalte-se, ainda, a necessidade de se tratar um ao outro com respeito, dignidade e amor, pois somente assim, alcança-se a fraternidade pregada pelo Cristianismo.

Certo é que o conceito de fraternidade foi amplamente construído dentro da corrente de pensamento cristã, como símbolo de sua doutrina inclusive. Mas também é um fato que a fraternidade ganhou significativa contribuição para os dias de hoje durante a Revolução Francesa.

A importância do tratamento dado à fraternidade pela Revolução Francesa pode ser facilmente exemplificada ao se recordar a tríade que marca o movimento: Liberté, Égalité, Fraternité $^{7}$.

A fraternidade foi tratada em meio à revolução como um sentimento de coesão para gerar a união da sociedade francesa nos ideais revolucionários.

Assim, foi dado a fraternidade um cunho jurídico e político durante a Revolução Francesa. Entretanto, talvez pela necessidade de se quebrar com os paradigmas anteriormente colocados, ela não tenha sido utilizada no período pós-revolucionário, uma vez que possuía fortes raízes no Cristianismo.

\footnotetext{
5 A união com Cristo inclui a união dos irmãos cristãos entre si, e implica, portanto, uma supressão dos limites naturais e históricos. Logo, por acima dos necessários limites dos diversos estados e do ordenamento hierárquico, há de reinar o "ethos" da igualdade e da fraternidade. (tradução livre)

${ }^{6}$ As diferenças em questão não existem se analisadas sobre o prisma "Deus e homens" e não sobre o prisma "homens e homens".

${ }^{7}$ Liberdade, Igualdade, Fraternidade (tradução livre)
} 


\title{
3.2. A FRATERNIDADE SOBRE O PRISMA JURÍDICO BRASILEIRO
}

O Brasil atualmente utiliza-se do modelo de Estado Democrático de Direito. Mendes, Coelho e Branco o definem da seguinte forma:

\begin{abstract}
Entende-se como Estado Democrático de Direito a organização política em que o poder emana do povo, que o exerce diretamente ou por meio de representantes, escolhidos em eleições livres e periódicas, mediante sufrágio universal e voto direto e secreto, para o exercício de mandatos periódicos, como proclama, entre outras, a Constituição brasileira. Mais ainda, já agora no plano das relações concretas entre o Poder e o indivíduo, considera-se democrático exercício efetivo não somente dos direitos civis e políticos, mas também e sobretudo dos direitos econômicos, sociais e culturais, sem os quais de nada valeria a solene proclamação daqueles direitos. (MENDES, COELHO e BRANCO, 2010, p. 213).
\end{abstract}

Por este modelo há uma grande preocupação em efetivar a participação popular frente aos rumos da política estatal. Desta forma, infere-se que é preocupação natural deste modelo o respeito pela dignidade da pessoa humana e, consequentemente, dos direitos fundamentais.

Portanto, a forma com que a fraternidade se espelha neste modelo estatal é diversa daquela oriunda dos modelos Liberal e Social. Enquanto que no primeiro, qualquer uso da fraternidade só pode ser percebido para garantir os direitos de liberdade, no segundo, qualquer uso da fraternidade somente pode ser percebido como forma de garantia dos direitos de igualdade.

No Estado Democrático de Direito é necessário ver no próximo a existência de um ser humano que necessita de respeito e condições que lhe garantam uma vida digna. Esta é a principal preocupação do Estado, uma vez que somente possuindo dignidade o cidadão consegue efetivar direitos políticos, sociais e econômicos. É exatamente a partir deste raciocínio que se insere a fraternidade neste modelo. É a possibilidade de aplicá-la para que a igualdade e a liberdade sejam equilibradas, ou seja, garante-se a liberdade aos sujeitos que participam do Estado, assim como também, a igualdade aos mesmos, primando sempre pela dignidade da pessoa humana.

Cumpre esclarecer, primeiramente, que a fraternidade não será conceituada de forma literal em textos legais, o que não impede uma aplicação prática, bem como a conceituação do termo sobre um viés jurídico.

A constituição brasileira de 1988 tem em seu texto a palavra fraternidade presente em seu preâmbulo.

\footnotetext{
Nós, representantes do povo brasileiro, reunidos em Assembleia Nacional Constituinte para instituir um Estado Democrático, destinado a assegurar o exercício dos direitos sociais e individuais, a liberdade, a segurança, o bem-estar, o desenvolvimento, a igualdade e a justiça como valores supremos de uma sociedade
} 
fraterna, pluralista e sem preconceitos, fundada na harmonia social e comprometida, na ordem interna e internacional, com a solução pacífica das controvérsias, promulgamos, sob a proteção de Deus, a seguinte CONSTITUIÇÃO DA REPÚBLICA FEDERATIVA DO BRASIL. (Constituição da República Federativa do Brasil, 1988 - grifo nosso)

Segundo seu texto constitucional, o Brasil define como objetivo uma "sociedade fraterna, pluralista e sem preconceitos, fundada na harmonia social'. Assim, a fraternidade é uma das direções que deve seguir o governo brasileiro a fim de alcançar a sociedade idealizada pelo constituinte. Importante, ainda, verificar que a fraternidade aparece ao lado de outros princípios, os quais também são metas para a "sociedade idealizada", quais sejam: "pluralista" e "sem preconceitos" e "harmonia social".

Todas estas características que são dadas à sociedade que o Brasil almeja alcançar estão intimamente ligadas com o próprio conceito de fraternidade, bem como o de dignidade da pessoa humana.

Assim, mesmo que o direito de fraternidade não esteja classificado expressamente no texto constitucional, como ocorre com os direitos de liberdade e de igualdade, não se pode afirmar que o direito não faz uso da fraternidade em meio as suas relações, inclusive jurídicas.

Considerando que a Constituição elege a construção de uma "sociedade fraterna" como um de seus objetivos. Portanto, a fraternidade é um princípio aplicável nas relações jurídicas, almejando-se a consolidação da aludida meta.

Aqui o conceito de fraternidade se assemelha, em seus fundamentos, com a construção cristã, pois gera o comando de respeito, compreensão, aceitação e cooperação com o próximo, mas, ao mesmo tempo, se afasta deste, pois o comando é gerado não porque somos todos filhos do mesmo Deus, mas por força de norma jurídica ${ }^{8}$.

Claro que, para tanto, é necessário um equilibrio entre os direitos de liberdade e de igualdade, pois estes também devem ser respeitados e tutelados frente ao Estado. A fraternidade, então, é um princípio que garante a dignidade da pessoa humana fazendo o controle entre os direitos de liberdade e de igualdade.

Como escreve Pizzolato:

\begin{abstract}
A fraternidade exprime-se na estreita correlação entre direitos e deveres, ou, ainda, entre liberdade e responsabilidade. É em nome de uma interdependência estrutural, em razão da qual o indivíduo se reconhece radical e estavelmente dependente, que a solidariedade se transforma em fraternidade, ou seja, numa solidariedade confinada ao próprio sujeito. (PIZZOLATO, 2008, p.120).
\end{abstract}

Aquini (2008) também entende a fraternidade como a forma de se dar efetividade aos direitos de liberdade e igualdade, advinda sempre da relação interpessoal:

\footnotetext{
${ }^{8}$ Portanto, refutado está o argumento de que a fraternidade somente poderia ser considerada um comando se baseado no Direito Natural.
} 


\begin{abstract}
A fraternidade é considerada um princípio que está na origemde um comportamento, de uma relação que deve ser instaurada com os outros seres humanos, agindo "uns em relação aos outros", o que implica também a dimensão da reciprocidade. Nesse sentido, a fraternidade, mais do que como um princípio ao lado da liberdade e da igualdade, aparece como aquele que é capaz de tornar esses princípios efetivos. Se considerarmos as duas categorias de direitos contempladas na DH [Declaração dos Direitos Humanos], o exercício da fraternidade pode ser aplicado a ambas, bem como aos direitos de liberdade e aos direitos civis e políticos (AQUINI, 2008, p.137).
\end{abstract}

Ropelato (2008) ao tratar a fraternidade sobre um viés político coloca-a como um 'princípio de construção social' e, apesar de trabalhar o conceito de forma política, vale transcrever suas ideias, pois podem ser trazidas para o campo do direito:

\begin{abstract}
Do ponto de vista político, a fraternidade coloca-se, antes de mais nada, como princípio de construção social, no qual o outro - se podemos definirmos irmãos - não é diferente de mim, mas outro eu mesmo. Seu significado relacional e, portanto dinâmico impele a buscar e a reconhecer mutuamente as fisionomias semelhantes entre os diversos sujeitos, grupos sociais e culturais. Além disso, a identificação de uma relação de fraternidade, como pertencimento recíproco, entre os atores sociais e políticos, implica pôr em prática relações de partilha e de responsabilidade, que certamente devem ser avaliadas em profundidade (ROPELATO, 2008, p.102).
\end{abstract}

A fraternidade é, também no direito, um princípio construtivo ${ }^{9}$, promovendo a dignidade da pessoa humana, fazendo com que cada um enxergue no próximo um ser humano que pode ser comparado consigo e que merece os mesmos direitos que são conferidos pelo Estado às pessoas.

Diferentemente dos direitos da liberdade e da igualdade, a fraternidade sempre será aplicável quando houver relação entre sujeitos. Como ressaltado por Ropelato (2008), a fraternidade tem um significado relacional, colocando em prática partilha e responsabilidade.

A fraternidade é responsável pelo desenvolvimento da sociedade para alcançar aquilo que parece ser um dos desafios do século XXI: promover a dignidade da pessoa humana. E, para tanto, a responsabilidade é individual, como afirma Aquini:

\begin{abstract}
A fraternidade, por sua vez, "responsabiliza" cada indivíduo pelo outro e, consequentemente, pelo bem da comunidade, e promove a busca de soluções para a aplicação dos direitos humanos que não passam necessariamente, todas, pela autoridade pública, seja ela local, nacional ou internacional. A consequência disso é uma valoração das entidades as sociativas e econômicas voltadas à busca da ampliação das condições econômicas e sociais. Um melhor nível cultural, educacional ou de geração de emprego pode ser alcançado pelo concurso de diferentes forças, responsavelmente fraternais, no interior de cada comunidade a que alguém pertence e na comunidade mundial. (AQUINI, 2008, p.138 e 139).
\end{abstract}

\footnotetext{
${ }^{9}$ O princípio construtivo difere-se de um princípio normativo, pois aquele se aproxima da construção de um valor, enquanto que este aproxima-se de um dever ser. Assim, o primeiro, encontra respaldo nas relações dos seres humanos que compõem o Estado, enquanto que o segundo encontra respaldo direto em texto normativo. Vale ressaltar que, o fato do princípio construtivo ser baseado em um valor, não implica na impossibilidade de ser utilizado pelo direito, sendo, em alguns casos (como é o caso da fraternidade), fonte norteadora de institutos jurídicos.
} 
A fraternidade é, então, um princípio construtivo, enraizado na alma humana, assim como a liberdade e a igualdade, presente em textos constitucionais e tratados internacionais, sempre expressando a necessidade de se promover a dignidade da pessoa humana. Importante ressaltar que tal objetivo necessitará da convivência harmônica entre a liberdade e a igualdade, sendo que a fraternidade pode ser justamente o princípio para a justificação e aplicação deste equilibrio.

\title{
4. A DIGNIDADE DA PESSOA HUMANA
}

A dignidade da pessoa humana é um dos fundamentos da República Federativa do Brasil, isto conforme o artigo $1^{\circ}$, inciso III da Constituição da República de $1988^{10}$.

Desta forma, todas as leis do país, bem como as relações dos cidadãos com o Estado, do Estado com os cidadãos e dos cidadãos entre si, devem ser espelhadas na dignidade da pessoa humana. Tal fato justifica a substituição do Código Civil de 1916 por um novo (qual seja, o Código Civil de 2002), pois a partir deste fundamento constitucional, a pessoa humana passa a ser a principal destinatária das leis (e não mais o patrimônio).

Diante do exposto, cabe tecer comentários sobre a definição da dignidade da pessoa humana.

Para buscar a definição de dignidade, Rosenvald embasa-se na teoria de Kant:

\begin{abstract}
"No reino dos fins tudo tem ou um preço ou uma dignidade. Quando uma coisa tem um preço, pode pôr-se em vez dela qualquer outra como equivalente; mas, quando uma coisa está acima de todo o preço e, portanto, não permite equivalente, então tem ela dignidade."

Percebe-se que a dignidade é noção da mais alta relevância axiológica, pois jamais o ser humano poderá servir de meio para os outros, sendo um fim em si mesmo. Kant revela que o fundamento da dignidade reside na autonomia da vontade, à medida que esta é uma faculdade de autodeterminação que apenas pode ser exteriorizada em seres racionais como imperativo categórico da ordem moral. (ROSENVALD, 2007, p.2).
\end{abstract}

Portanto, dizer sobre a dignidade da pessoa humana é afirmar que o ser humano somente pode ser considerado como um fim em si mesmo, não podendo, sobre ele, recair nenhuma condicionante que the diminua ou acrescente. Ressalte-se que a dignidade da pessoa

10 “Art. $1^{\circ}$ A República Federativa do Brasil, formada pela união indissolúvel dos Estados e Municípios e do Distrito Federal, constitui-se em Estado Democrático de Direito e tem como fundamentos: (...) III - a dignidade da pessoa humana;" (BRASIL, 1988) 
humana é um conceito que transcende a capacidade, cidadania ou qualquer outro que restrinja direitos e deveres dos seres humanos.

E a dignidade, sendo um fundamento da República, deve ser espelhada em meio a normas e preceitos. Mais adiante no texto constitucional, a dignidade da pessoa humana é tratada como principio. Por isso, a possibilidade de se afirmar que a dignidade da pessoa humana é, ao mesmo tempo, valor e princípio.

Importante observar, ainda, que seguindo as características do Estado Democrático de Direito, o cidadão é convocado para que, ao lado do Estado, seja responsável pela promoção da dignidade da pessoa humana, seja no planejamento familiar, com as crianças, adolescentes e com idosos. Não seria exagero dizer que este preceito constitucional (de promoção da dignidade) é de responsabilidade de toda a sociedade. Ou seja, é devido por todos e a todos.

Dada à importância do princípio da dignidade da pessoa humana, é possível afirmar que não cabe relativização do preceito. Assim discorre Rosenvald:

\begin{abstract}
A dignidade da pessoa humana seria um juízo analítico revelado a priori pelo conhecimento. O predicado (dignidade) que atribuo ao sujeito (pessoa humana) integra a natureza do sujeito e um processo de análise o extrai do próprio sujeito. Sendo a pessoa um fim em si - jamais um meio para se alcançar outros desideratos -, devemos ser condu zidos pelo valor supremo da dignidade. (ROSE NV ALD, 2007, p.3)
\end{abstract}

E é exatamente pela impossibilidade de relativizar a dignidade da pessoa humana, que, nos casos concretos, quando houver choque entre dois princípios, sendo um destes, o princípio da dignidade da pessoa humana, esse deve sempre prevalecer em detrimento do outro.

O ser humano é o fim pelo qual a norma se destina, portanto, a mesma norma que foi feita para the servir, deve, ao mesmo tempo, primar pela sua dignidade. Assim, é possível inferir que a dignidade antecede ao direito. Assim explica Rosenvald:

\footnotetext{
A dignidade, todavia, antecede ao próprio direito, pois é um atributo de qualquer pessoa - como valor ético, enquanto o direito resulta de circunstâncias e posicionamentos diferentes. A dignidade situa o ser humano no epicentro de todo o ordenamento jurídico, como protagonista, tanto no âmbito do direito público como no do direito privado, repelindo qualquer atentado proveniente de outras pessoas e dos poderes públicos. (ROSENVALD, 2007, p.8)
}

Segundo o Estado Democrático de Direito é que a dignidade da pessoa humana ganha traços de definição abrangentes. Primeiro, porque, como determinado acima, é uma das bases do Estado. E também, porque, a dignidade passa a ser considerada levando-se em conta a coletividade e não os seres humanos de forma individual. Assim, respeitar a dignidade não é somente preceito estatal, mas também das pessoas que o compõem. 
Quando um ser humano pensa em exercer uma conduta, procurando a sua dignidade (ou alcançar a felicidade), não pode fazê-la se passar por cima da dignidade de seu semelhante. Isto porque se o ser humano tem um fim em si mesmo, como discutido acima, o fim do outro também deverá ser considerado pela coletividade. Nas palavras de Rosenvald:

Se o fim natural de todos os homens é a realização de sua própria felicidade, não basta agir de modo a não prejudicar ninguém. Há ainda uma função positiva, que consiste em privilegiar, na medida do possível, os fins alheios. Sendo o sujeito um fim em si mesmo, os fins de outrem serão por mim considerados também como meus. (ROSENVALD, 2007, p.7).

É claro que a observância da dignidade do outro passa por limites aceitáveis pela sociedade. Ou seja, em caso de perigo, por exemplo, não é exigível do ser humano que se coloque em perigo para assegurar a segurança do próximo.

Mas, importante ressaltar que, a dignidade da pessoa humana encontra limite exatamente nos fins do outro. Rosenvald (2007) explica que a dignidade da pessoa humana significa que fazemos parte de uma Humanidade. Portanto, qualquer pessoa é livre para alcançar os fins aos quais se destina, entretanto, "se a finalidade para a qual esse dinamismo se dirige for ofensiva à dignidade alheia, será o autor do ilícito qualificado como desmerecedor da humanidade que lhe fora concedida" (ROSENVALD, 2007, p.19) e, finaliza, dizendo que o ordenamento deverá estabelecer parâmetros para compatibilizar a dignidade das pessoas. Mas de que forma?

\begin{abstract}
Para que o princípio da dignidade da pes soa humana exercite eficácia jurídica positiva, caberá ao Estado ofertar igualdade de chances (não de resultados, o que seria paternalismo) mediante condições mínimas que não excluam um universo de oportunidades e permitam a cada um o desenvolvimento de sua personalidade e autonomia privada. Adotando a teoria da justiça de John Rawls, a tarefa do sistema jurídico consiste em conceder um conjunto de situações materiais indispensáveis que simbolizariamuma espécie de carteira de acesso à vida, bens essencial e umprincípio de autodeterminação. A partir do acesso a um núcleo de condições materiais, cada pessoa poderá prevalecer por seus méritos reais. (ROSENVALD, 2007, p. 202).
\end{abstract}

Desta forma, ao Estado cabe ofertar aos sujeitos igualdades de chances para que, tomando posse de condições mínimas, as pessoas sejam capazes de promover, por si só a dignidade. Também cabe ao Estado criar e institucionalizar formas de exercer o controle efetivo da dignidade nas relações privadas.

Assim, percebe-se que a dignidade da pessoa humana é, ao mesmo tempo, valor (pois, depende de um júzo qualitativo que varia de grupo social para grupo social) e ao mesmo tempo princípio (ao passo que sintetiza um comando aberto constitucional). Infere-se, também, que a 
dignidade significa que o ser humano tem um fim em si mesmo, não podendo ser reduzido a qualquer forma de valoração. Diante deste apontamento, afirma-se a impossibilidade de relativizar a dignidade da pessoa humana, que deve ser considerada de forma plena. Entretanto, isto não significa que não possua limites. A dignidade da pessoa humana (considerada de forma individual) encontra limites na dignidade do outro. Assim, uma determinada pessoa não pode procurar o seu fim, infringindo a dignidade do próximo. A sociedade necessita, portanto, de criar um sentimento de solidariedade entre os sujeitos.

\section{FRATERNIDADE, FUNÇÃO SOCIAL E DIGNIDADE}

Cada ser humano, buscando alcançar a sua dignidade, procura um bem da vida, almejando atingir a sua felicidade.

Não é difícil a conclusão que se cada ser humano buscasse individualmente o seu bem da vida, a sociedade seria uma completa bagunça.

Importante ressaltar que o ser humano comunica-se e se relaciona com seus semelhantes. Segundo Rosenvald (2007), o ser humano vive em sociedade e, por isso, não cumpre os seus fins de forma isolada. Assim, "a ideia do bem comum concerne à existência humana e à vida do homem em sociedade" (ROSENVALD, 2007, p.63).

Desta forma, a soma do bem da vida individualizado (ou da felicidade individual) de todos os seres humanos revela o bem comum, que deve ser seguido por todos que vivem na mesma sociedade, alcançando o seu objetivo primaz, que é a possibilidade da convivência harmônica.

Entretanto, a eleição do bem comum varia de acordo com o modelo estatal escolhido por uma nação. Levando-se em consideração o Estado Liberal, o bem comum será voltado para a liberdade individual. Desta forma, desconsidera-se qualquer forma de um "agir solidário". Já em modelos estatais coletivistas, como o Social e o Socialista, considera-se o bem comum aplicável somente pelo/ao Estado, desconsiderando as vontades individualmente colocadas. Assim explica Rosenvald:

\footnotetext{
A concepção individualista - vigente a partir do Estado liberal do século XIX vislumbra os homens individualmente considerados como realidade. A humanidade seria a soma de todas as pessoas e a sociedade seria uma ficção. Não se cogita de solidariedade, pois o bem comum seria mera soma de bens individuais em um conceito aritmético.

Emoutro pólo se encontra o coletivis mo. A coletividade seria a es sência da sociedade, pois o individuo se despersonaliza em favor do todo. A pessoa não exerce direitos perante a sociedade, pois ele apenas existe em função dela. Só ao Estado se atribui o bem comum. (ROSENVALD, 2007, p.63).
} 
Verifica-se, a partir do trecho acima, que a visão sobre o bem comum diverge nesses dois tipos de concepções. Enquanto na concepção individualista o bem comum foca somente a individualidade, esquecendo-se do coletivo, a concepção coletiva preocupa-se somente com a visão do todo, não ponderando sobre a individualidade dos sujeitos que compõem o Estado.

Tratam, portanto, de visões parciais, sendo que uma necessariamente complementa a outra. É exatamente essa conjugação que o Estado Democrático de Direito preocupa-se em realizar. No aludido modelo, o bem comum é considerado de forma coletiva, bem como de forma individual. Assim, para efetivar o sistema, necessária a criação de um sentimento de "solidariedade" entre os sujeitos, uma vez que a pessoa deve ter garantido o seu bem comum (considerado de forma individual), mas, ao mesmo tempo, primar pela garantia do bem comum destinado a todas as pessoas (bem comum coletivo).

Rosenvald utiliza-se de Enrique Luño Pena para explicar a definição de bem comum dentro do Estado Democrático de Direito:

O bem comum é o bem ou suficiência de meios de vida de cada um, considerando
solidário em relação ao bem dos demais. É o meu bem, relativamente,
proporcionalmente ao deste, daquele e de todos os demais. Se um patrão procura
aumentar seu patrimônio privado em detrimento dos trabalhadores, distribuindo
miséria em torno de si, infringe o bem comum, não por aumentar seus bens, mas por
prejudica-los. (PENA apud ROSENVALD, 2007, p.69).

No exemplo acima, o patrão que procura aumentar seu patrimônio está procurando um bem da vida (considerado de forma individual, o que seria completamente aceitável segundo a concepção liberal). Entretanto, ao fazê-lo à custa de outras pessoas - pois espalha miséria ao seu redor - infringe o bem comum (considerado de forma coletiva) e, por isso, pratica uma conduta ilícita, dentro dos ideais do Estado Democrático de Direito.

Pizzolato trata da forma com que os direitos devem ser exercidos, ou seja, em consonância com o bem comum:

Os direitos devem ser exercidos em harmonia com o bem comum. Não cabe, portanto,
nenhuma afirmação apriorística de liberdade, mas o reconhecimento de um contínuo
entrelaçamento dos direitos entre si e com as exigências sociais, o reconhecimento,
portanto, da necessidade de balanceamento. Esse balanceamento de direitos
candidata-se (já o fez) como espaço da composição "fraternal" dos direitos.
(PIZZOLATO, 2008, p.124)

Necessário observar, portanto, o equilibrio entre direitos, para assegurar a todos a vida com dignidade. E como ressaltado pelo autor acima, a fraternidade toma este papel de mediadora entre os direitos, viabilizando a busca do bem comum. 
Ressalte-se que na busca pelo bem comum as pessoas celebram negócios jurídicos (contratos). Desta forma, busca-se o oferecimento de determinada obrigação (que pode ser de dar, fazer ou não fazer) esperando-se, em troca, uma contraprestação.

Anteriormente ao Código Civil de 2002 o contrato era norteado por princípios que são chamados de clássicos. São mandamentos oriundos da ordem liberal instaurada ao redor do mundo capitalista. Sobre estes princípios, fundamenta Theodoro Júnior:

\begin{abstract}
Todo o sistema contratual se inspira no indivíduo e se limita, subjetiva e objetivamente à esfera pessoal e patrimonial dos contratantes. Três são, portanto, os princípios clássicos da teoria liberal do contrato: a) o da liberdade contratual, de sorte que as partes, dentro dos limites da ordem pública, podem convencionar o que quiserem e como quiserem; b) o da obrigatoriedade do contrato, que se traduz na força de lei atribuída às suas clausulas (pacta sunt servanda); e c) o da relatividade dos efeitos contratuais segundo o qual o contrato só vincula as partes da convenção, não beneficiando nem prejudicando terceiros (res inter alios acta neque nocet neque prodest). (THEODORO JÚNIOR, 2008, p.1 e 2)
\end{abstract}

Desta forma, verifica-se que os princípios clássicos dos contratos são três: a liberdade contratual, restrita somente ao texto legal; o fato de que o contrato faz lei entre as partes; e, o fato de que o contrato não pode vincular terceiros, de forma positiva ou negativa.

Outro ponto importante de ser abordado é o fato de que antes as obrigações eram voltadas somente para o devedor. Nos moldes do direito civil contemporâneo as obrigações são vistas como um ato complexo, permeado por diversas "sub-obrigações". Com isso, a obrigação não mais foca somente no devedor, pois ambos os contratantes possuem deveres e direitos uns para com os outros.

Assim, o bem comum nas relações obrigacionais exprime-se na "solidariedade mediante a cooperação dos indivíduos para a satisfação dos interesses patrimoniais recíprocos, sem comprometimento dos direitos da personalidade e da dignidade do credor e do devedor" (ROSENVALD, 2007, p.70).

Neste contexto, inserem-se os novos princípios contratuais, revelados pelo Código Civil de 2002 que são: a função social dos contratos; a boa-fé objetiva; e, o equilibro econômico.

Para explicar a necessidade dos novos preceitos, escreve Theodoro Júnior:

\footnotetext{
Éinegável, nos tempos atuais, que os contratos de acordo coma visão socialdo Estado Democrático de Direito, hão de submeter-se ao intervencionismo estatal manejado como propósito de superaro individualismo egoístico e buscar a implantação de uma sociedade presidida pelo bem-estar e sob "efetiva prevalência da garantia jurídica dos direitos humanos”. (THEODORO JÚNIOR, 2008, p.4)
}

Assim, o bem comum buscado pelos contraentes das obrigações (ou contratantes) deve respeitar a dignidade daqueles que fazem parte do ato, sob pena de invalidade. O dever de 
solidariedade entre as partes é medida que se impõe. Se analisada a necessidade de respeitar-se a dignidade dos contratantes, diz-se que está se analisando a boa-fé objetiva.

Em contrapartida, se analisada a necessidade de respeitar-se a dignidade de terceiros não envolvidos na relação contratual, diz-se que está se analisando a função social dos contratos.

Em um primeiro momento, pode parecer-nos que a observância a estes novos preceitos extirpa a liberdade contratual. Entretanto, não é o que ocorre. A obrigatoriedade de respeitar-se o bem comum (considerado individualmente e coletivamente), a dignidade dos contratantes e até mesmo a função social dos contratos, garante, não só uma igualdade material entre os mesmos, como os coloca em verdadeira condição de liberdade contratual, ao passo que um não tem que subordinar-se ao outro.

A função social dos contratos (assim como a boa-fé e o equilibro econômico) é preceito que exemplifica o uso, pelo Código Civil de 2002, dos seus princípios fundadores, quais sejam: a eticidade, a socialidade e a operabilidade. Assim exemplifica Theodoro Júnior:

\footnotetext{
O Código Civil de 2002 se anuncia como arauto de novos rumos para o direito privado, as sinalados pela eticidade, socialidade e economicidade.

Essas características se fazem notar com maior realce no campo do contrato, onde o Código destaca normas explícitas para consagrar a boa-fé objetiva, a função social dos contratos e a submissão aos efeitos da revisão contratual para reequilíbrio de sua equação econômica. (THEODORO JÚNIOR, 2008, p.IX)
}

Entretanto, as novas normas que devem orientar os contratos, quais sejam: a boa-fé, a função social e a necessidade do equilibrio econômico, não desintegram os componentes antigos do contrato (liberdade contratual, lei entre as partes e impossibilidade de obrigação para terceiros estranhos ao contrato). Somente enriquecem o sistema, fazendo com que preceitos de solidariedade sejam aplicados aos contratos. Nos dizeres de Theodoro Júnior, "O que se deu foi o acréscimo aos clássicos, de princípios forjados sob o impacto das atuais idéias de socialidade e solidarismo que a ordem constitucional valorizou" (2008, p.IX).

Assim, a liberdade contratual ainda vigora na elaboração dos contratos, mas é preceito relativizado pela função social, ao passo que, para a validade do contrato não basta a autonomia das vontades, mas, também, a análise das novas regras trazidas pelo código.

Portanto, cumpre esclarecer que a autonomia privada deve ser exercida dentro dos limites tratados pela Constituição. Conforme Theodoro:

\footnotetext{
A autonomia privada é o espaço dentro do qual as pessoas exercem, na vida econômica, a liberdade que a Constituição declara e assegura como garantia fundamental. É claro que exigências do solidarismo e socialidade, também preconizadas pela sistemática constitucional, diminuem o espaço de atualização da
} 
liberdade, se comparada com a dos tempos do liberalismo exacerbado. (THEODORO JÚNIOR, 2008, p.X)

Como dito pelo autor acima, se compararmos a liberdade contratual baseada no Estado Democrático de Direito com a liberdade contratual baseada no Estado Liberal, ver-se-á uma grande diferença.

Uma das ferramentas para limitar a liberdade contratual é exatamente a função social dos contratos. Rosenvald explica a funcionalidade desta na relação contratual:

\begin{abstract}
“A liberdade de contatar será exercida em razão e nos limites da função social do contrato". A cláusula geral do artigo 421 do Código Civil indica que a funcionalidade da relação obrigacional reside na preservação da harmonia de seus participantes. A intervenção da sociedade sobre o contrato será no sentido de estimular o adimplemento da relação obrigacional, mediante a cooperação dos contratantes, para que seja possível o resgate da liberdade que foi cedida em razão do contrato. (ROSENVALD, 2007, p.71)
\end{abstract}

Desta forma, a função social dos contratos dificulta que um contrato seja feito de forma a onerar tanto uma das partes, dificultando ou tornando impossível a execução da obrigação pactuada $^{11}$.

É possível perceber, de forma clara, a ligação entre a dignidade da pessoa humana e a função social dos contratos. Um existe para viabilizar a concretude do outro. Assim, atendendo ao preceito constitucional da dignidade da pessoa humana como um fundamento da República, a função social dos contratos é o instituto que irá garantir a sua efetividade em meio às obrigações.

Como explicitado anteriormente neste artigo, à pessoa humana não pode ser conferida valoração de coisa. Assim, o direito civil deve tratá-la como merecedora de respeito e dignidade, mesmo em meio às relações obrigacionais. Nesse sentido:

Nada, como efeito, justifica o tratamento da pessoa humana, no relacionamento jurídico, como coisa ou como simples número de uma coletividade. (...) Não pode permitir que em nome da liberdade negocial a força econômica privada seja desviada para empreendimentos abusivos, incompatíveis com o bem estar social e com os valores éticos cultivados pela comunidade. (THEODORO JÚNIOR, 2008, p.34)

Entretanto, ainda devem-se colacionar a estes dois temas, a fraternidade. Em um primeiro momento cumpre esclarecer que durante esta pesquisa foi citado, diversas vezes, o termo "solidariedade", assim como ocorrerá em muitas outras. E solidariedade exprime a

\footnotetext{
11 Pelo explicado, pode-se citar o artigo 478 do Código Civil, o qual trata da resolução contratual devido à onerosidade excessiva. In verbis: "Art. 478. Nos contratos de execução continuada ou diferida, se a prestação de uma das partes se tornar excessivamente onerosa, com extrema vantagem para a outra, em virtude de acontecimentos extraordinários e imprevisíveis, poderá o devedor pedir a resolução do contrato. Os efeitos da sentença que a decretar retroagirão à data da citação." (BRASIL, 2002).
} 
necessidade de agir em cooperação com o próximo, seja ele o outro polo da obrigação contraída, ou integrante da humanidade, no geral. Assim, sabe-se que solidariedade e fraternidade não possuem o mesmo significado, mas para os fins aos quais se destina esta pesquisa, podem ambas ser consideradas como uma aplicação jurídica da fraternidade em meio às relações sociais, ao passo que objetivam a mesma finalidade, qual seja: cumprimento, através de preceitos morais, da ajuda necessária por um ser humano para com o outro, buscando-se sempre a dignidade da pessoa humana, e, desta forma, reafirmando o Estado Democrático de Direito.

Tratado destes "parênteses" passa-se a analisar a utilização da fraternidade em meio ao direito contemporâneo, sendo necessária a transcrição de Rosenvald:

\begin{abstract}
Na lição de Paulo Bonavides, com o advento dos direitos fundamentais da terceira geração "um novo polo jurídico de alforria do homem se acrescenta historicamente aos da liberdade e da igualdade. Dotados de altíssimo teor de humanismo e universalidade, têm por primeiro destinatário o gênero humano mesmo, num momento expressivo de sua afirmação como valor supremo em termos de existencialidade concreta".

De fato, o constitucionalismo voltou-se inicialmente à afirmação dos direitos individuais, posteriormente aos direitos sociais e em um terceiro momento, à concretização do direito à fraternidade. Eles não são nem individuais nem sociais, atuamem outro paradigma, o da humanidade, expandindo o conceito de dignidade da pessoa humana. (ROSENVALD, 2007, p.174).
\end{abstract}

Assim, a fraternidade é um meio de proporcionar o equilibrio entre os direitos de liberdade e os de igualdade, tornando viável o Estado Democrático de Direito. Também é responsável por dar concretude à dignidade da pessoa humana. Se um sujeito pratica uma ação, levando em consideração o texto legal, para preservar a dignidade de outra pessoa, estará alcançado o objetivo do Estado. Entretanto, diante da lacuna, ou de um preceito aberto como, por exemplo, a necessidade do contrato ser realizado com observância da sua função social, somente se analisados valores de fraternidade (ou solidariedade) é que o fim procurado será atendido.

Theodoro Júnior também relaciona os temas acima tratados:

Para ter-se uma noção do que venha a ser es sa nova função atualmente no campo dos negócios jurídicos, destaca FRANCISCO AMARAL que o exercício da autonomia privada, nos nossos tempos, "deve orientar-se não só pelo interesse individual, mas também pela utilidade que possa ter na consecução dos interesses gerais da comunidade".

A idéia de justiça social, no terreno do contrato, dessa maneira, aparece agora com uma nova dimensão "que se insere em uma outra categoria, a justiça geral, que diz respeito aos deveres das pessoas em relação à sociedade, superando-se o individualismo jurídico em favor dos interesses comunitários". (THEODORO JÚNIOR, 2008, p.14) 
Encontra-se, pois, a ligação pretendida entre os temas. A fraternidade é a fonte para a função social dos contratos, e somente com a sua observância é que se chega à dignidade da pessoa humana, em meio às obrigações contraídas pelas pessoas.

Cumpre destacar que o princípio construtivo da fraternidade, previsto no preâmbulo da Constituição, não é aplicável somente nas relações do Estado com os sujeitos, mas nas relações particulares também. Conforme Rosenvald:

\begin{abstract}
Quando o preâmbulo da Constituição Federal ostenta a efetivação de valores de uma "sociedade pluralista, fraterna e sem preconceitos", não dirige a sua supremacia apenas aos obstáculos criados pelo Estado a uma vida solidária, mas também à sociedade, que não raramente atua de forma opressiva, aniquilando o direito de pessoas a uma existência digna. Portanto, nas relações privadas o princípio da solidariedade atuará em diversos campos, exemplificadamente, na função social da propriedade (art. 1.228 do CC); na alusão à cláusula geral da "comunhão plena de vida" como base da família (art. 1.511 do CC). (ROSENVALD, 2007, p.175).
\end{abstract}

Desta forma, não cabe somente ao Estado efetivar a fraternidade em meio às relações sociais. Quando a obrigação de observância da fraternidade passa para as relações particulares, o Estado está requisitando às pessoas que o ajudem a cumprir esta meta. Cumpre esclarecer que o chamamento do cidadão para atuar ao lado do Estado é regra do Estado Democrático de Direito.

Ainda sobre a interferência do Estado sobre o privado, escreve Rosenvald:

\begin{abstract}
Hoje a autonomia privada não é apenas inserida no contexto da ordem econômica constitucional. Ela também é uma especificação do princípio da dignidade da pessoa humana, que se consagra e tutela a existência de uma dimensão vital para que todo ser humano possa desenvolver e afirmar socialmente a sua personalidade. A boa-fé atua em companhia do principio da autonomia privada. Ambos informam o direito das obrigações em uma atuação bipolar. A autonomia é contida nos limites da estrutura e do tipo contratual. A boa-fé significa a aceitação da interferência de elementos externos na intimidade da obrigação, regulando a extensão e o exercício dos direitos subjetivos. A dignidade da pessoa humana se concretiza em variadas vertentes. Daí resulta uma gama de enfrentamentos: no direito privado, a ponderação entre o direito subjetivo e a sua função social, com imposição de boa-fé nos negócios jurídicos; no plano superior da Constituição, a inevitável colisão entre os princípios da solidariedade e autonomia privada. (ROSENVALD, 2007, p.208).
\end{abstract}

Como exemplo da atuação da fraternidade, portanto, pode-se considerar a função social dos contratos. Rosenvald (2007) explicita que a função social dos contratos é um uso da fraternidade que considera as pessoas que não estão envolvidas de forma direta no contrato (como por exemplo, um contrato que denigra a dignidade da pessoa humana de forma geral desrespeita a função social) e a boa-fé objetiva é um uso da fraternidade para com os envolvidos no contrato (como por exemplo, um contato que possui vício de conhecimento prévio desrespeita a boa-fé). 
Da mesma forma, explica Theodoro Júnior:

A função social do contrato consiste em abordar a liberdade contratual em seus reflexos sobre a sociedade (terceiros) e não apenas no campo das relações entre as partes que o estipularam (contratantes). Já o princípio da boa-fé fica restrito ao relacionamento travado entre os próprios sujeitos do negócio jurídico. (THEODORO JÚNIOR, 2008, p.30)

A partir desta explicação é possível, inclusive, ampliar o objeto desta pesquisa, ao passo que podemos afirmar que a boa-fé objetiva também demonstra um uso normativo da fraternidade pelo direito.

Outra anotação importante, feita por Rosenvald, é no caminho de que a conciliação entre boa-fé (leia-se, inclusive, a função social dos contratos), solidariedade (leia-se fraternidade) e dignidade da pessoa humana possibilita uma leitura conjugada entre a Constituição e o Direito Civil, além de reafirmar as bases do Estado Democrático de Direito, vejamos:

\begin{abstract}
Ess a tarefa de conciliação entre os princípios da boa-fé, solidariedade e dignidade da pessoa humana propicia um rompimento com a tradicional pers pectiva de seção entre o direito civil e a Constituição. Mais ainda, objetiva demonstrar que o vetor axiológico da dignidade, como princípio unificante do Estado Democrático, não incide imediatamente sobre a boa-fé, mas, antes, é mediatizado pela diretriz da solidariedade, que se aproxima da boa-fé objetiva em grau mais próximo. (ROSENVALD, 2007, p.182).
\end{abstract}

Claro que esta conciliação não é tarefa fácil, ademais porque confronta com princípios anteriores da teoria geral dos contratos. Theodoro Júnior cita Sylvio Capanema de Souza para exemplificar que este é um desafio que afronta os novos rumos do direito civil:

Para SYLVIO CAPANEMA DE SOUZA, “o grande desafio que se abre para os juízes, e que poderá transformar o novo Código em terrível frustração ou redenção ética, é o trabalho de conciliar estes novos conceitos de boa-fé e função social com os princípios tradicionais da autonomia da vontade e de força obrigatória dos contratos, que não foram e nem poderiam ser revogados. (...) O Novo Código não representa a morte dos valores fundamentais que sempre inspiraram o mundo dos contratos, e sim seu temperamento para adaptá-los a um tempo, preocupado com a construção da dignidade do homem e de uma sociedade mais justa e fraternal". (THEODORO JÚNIOR, 2008, p.X e XI)

Portanto, apesar de difícil tarefa, necessária é a conciliação entre os direitos de liberdade (primando pelos antigos princípios norteadores dos contratos) com os direitos de igualdade (primando pelos novos princípios norteadores dos contratos). Somente assim será possível alcançar de forma plena a dignidade da pessoa humana.

E acredita-se que a fraternidade é o elemento determinante para tornar tal caminho possível, pois é o principio construtivo capaz de balancear os dois lados da moeda, sem causar maiores prejuízos à liberdade contratual, e visando sempre o bem estar da coletividade. 
Desta forma, verifica-se que a partir da fraternidade (como meta para a construção da sociedade que a Constituição da República brasileira de 1988 almeja), desenvolvem-se institutos jurídicos que visam exercer o controle da liberdade individual assegurando o mínimo de igualdade entre as pessoas. Um destes institutos é justamente o princípio da função social dos contratos, pelo qual as partes, ao celebrarem um contrato, devem preocupar-se em estabelecer cláusulas que não lesionem nem a si mesmas e nem tampouco terceiros, que a priori não estão envolvidos naquela relação jurídica.

Assim, pretende-se tornar viável a dignidade da pessoa humana (que é uma das bases da República do Brasil), confirmando o modelo de Estado Democrático de Direito.

\section{CONSIDERAÇÕES FINAIS}

Neste artigo buscou-se evidenciar a fraternidade através de um conceito jurídico, podendo ser exprimido através da função social dos contratos.

Para tanto, em um primeiro momento, buscou-se a definição do instituto da função social dos contratos. Neste estudo verificou-se que a função social (no direito brasileiro) é instituto decorrente do Novo Código Civil de 2002, que tem como princípios norteadores a eticidade, a socialidade e a operabilidade. O Código Civil de 2002 preocupa-se em resguardar a dignidade da pessoa humana; mesmo que para isso seja necessária a intervenção estatal na esfera privada.

E assim acontece com os contratos. Se, em um primeiro momento, parte-se do pressuposto de que o contrato é um acordo livre e desimpedido entre as partes contratantes, fazendo lei aos pactuantes, com a análise da sua função social, o plano de validade e eficácia do pactuado está condicionado à necessidade de se atender à função social. Ou seja, se aquele contrato não for viável para a sociedade como um todo, ou melhor, se não primar pela dignidade da pessoa humana, será considerado nulo, mesmo partindo da vontade dos contratantes. Assim, verifica-se que a liberdade contratual não é plena e seu limite não é somente aquele desenhado pela lei (análise da legalidade contratual); pois passa também por uma avaliação valorativa de preservação da dignidade da pessoa humana.

Em um segundo momento, analisou-se a evolução do conceito de fraternidade. Com certeza, é no Cristianismo que a evolução deste ganha o seu auge. Segundo esta doutrina, todo 
ser humano deve se tratar mutuamente com espírito de amor e fraternidade, pela simples razão de serem humanos. Tal mandamento encontra respaldo no fato de todos sermos irmãos, vez que somos filhos do mesmo Deus. A partir de então, a fraternidade ganha uma conotação universal, pois é destinada a todos aqueles que quiserem professar a fé cristã. Segundo algumas correntes do pensamento cristão, a fraternidade é devida a todas as pessoas, independentemente de comungarem a mesma fé.

Entretanto, é a Revolução Francesa que confere à fraternidade um cunho político, ao tratá-la em seu lema e priorizá-la, ao lado da igualdade e da liberdade, como metas para uma sociedade justa. Vale ressaltar que este conceito de fraternidade estava adstrito aos limites territoriais franceses, bem como a uma pequena parcela de pessoas oriundas da revolução. Assim, a fraternidade ganha força política, mas perde seu caráter universal conferido pelo Cristianismo.

No modelo Estatal Democrático de Direito, que busca sempre a proteção da dignidade da pessoa humana, para cumprir seu objetivo estão sempre equacionados os direitos de liberdade e de igualdade. E é exatamente neste ponto que se enquadra a aplicação da fraternidade.

A fraternidade no modelo do Estado Democrático de Direito é um principio construtivo (ao passo que é um valor, cuja aplicação impõe-se por mandamento constitucional) que visa equilibrar os direitos de liberdade com os direitos de igualdade, visando alcançar a dignidade de todas as pessoas que compõem o Estado.

Analisou-se, ainda, a dignidade da pessoa humana e verificou-se que esta determina que a pessoa deva ser considerada como um fim em si mesma, não podendo ser valorada de alguma forma, ou tratada como uma coisa. Verificou-se, ainda, que a dignidade da pessoa humana é um dos fundamentos da República brasileira e que, por este motivo, é uma das chaves de interpretação para todos os casos concretos.

Assim, relacionando os conceitos de fraternidade, função social dos contratos e dignidade da pessoa humana, conclui-se que a fraternidade é uma das metas de construção da sociedade, almejada pelo preâmbulo da Constituição, sendo, por este motivo, um princípio construtivo (valor) aplicável sempre que necessário. Verifica-se, ainda, que a fraternidade é uma forma de equilibrio entre os direitos, sejam eles de liberdade ou de igualdade, oferecendo ao ser humano a possibilidade de escolha (livre iniciativa), mas conservando o mínimo de igualdade necessária para com seu semelhante. 
Ao relacionar-se com o outro, segundo os ditames da fraternidade, o sujeito deve respeitar a dignidade do seu semelhante, agindo com espírito de solidariedade.

Já a função social dos contratos é preceito civil que visa regulamentar, ao lado de outros preceitos, as relações obrigacionais. Por este princípio, os contratantes não podem contratar algo que os lesione ou cause prejuízos à humanidade.

O contrato deve ser útil para a sociedade, sendo que, uma vez infringida esta norma, a penalidade é a nulidade do contrato. Percebeu-se que esta é uma clara forma de controlar os direitos de liberdade do sujeito para assegurar um mínimo de igualdade a todos.

Fica claro, então, que a função social é um instituto que coloca em prática a fraternidade. Tal tese pode também ser comprovada pelo seguinte fato: a função social dos contratos é uma cláusula aberta, cabendo a interpretação de seu respeito ou violação ao julgador no caso concreto. E, para avaliar a situação, este deverá recorrer aos valores fraternais entendidos por aquela sociedade.

Todo este arcabouço jurídico é montado para preservar a dignidade da pessoa humana. Se o contrato não respeitar a dignidade da pessoa (seja de um dos contratantes, ou de um terceiro, que a um primeiro momento, não tem nenhuma relação com o contrato), não terá atendido a sua função social e, portanto, não terá sido feito com base na fraternidade, sendo extirpado do mundo jurídico e fático.

Considera-se, assim, que a hipótese sugerida neste trabalho foi comprovada, ao passo que a função social dos contratos pode ser considerada como um uso jurídico do princípio construtivo da fraternidade. Mais que isso, percebe-se, a prima facie, que outros institutos jurídicos, como por exemplo, a boa-fé objetiva, aplicável na esfera contratual, também espelha um uso jurídico da fraternidade. Entretanto, para que tal tese seja afirmada e justificada, com plena certeza, necessária se faz uma pesquisa mais aprofundada no tema.

\section{REFERÊNCIAS BIBLIOGRÁFICAS}

AQUINI, Marco. Fraternidade e direitos humanos. In: Baggio, Antônio Maria (org.). O princípio esquecido/1. São Paulo: Cidade Nova; 2008. Cap. 6, p.127-152.

ARENDT, Hannah. O conceito de amor em Santo Agostinho: ensaio de interpretação filosófica. Lisboa: Instituto Piaget; 1997.

AZEVEDO, Álvaro Villaça. Teoria Geral dos contratos típicos e atípicos. São Paulo: Editora Atlas. 2009. 
BAGGIO, Antônio Maria. A idéia de fraternidade em duas Revoluções: Paris 1789 e Haiti 1791. In: Baggio, Antônio Maria (org.). O princípio esquecido/1. São Paulo: Cidade Nova; 2008. Cap. 1, p.25-56.

BRASIL. Código Civil (2002). Código Civil 4 em 1, São Paulo, Saraiva, 2010.

Brasil. Código Civil (2002). Código civil brasileiro e legislação correlata. - 2. ed. Brasilia: Senado Federal, Subsecretaria de Edições Técnicas, 2008.

BRASIL. Constituição (1988). Constituição [da] Republica Federativa do Brasil. Brasilia, DF: Senado Federal.

DINIZ, Maria Helena. Curso de Direito Civil brasileiro. 28 ${ }^{\text {a }}$ Ed. São Paulo: Saraiva. 2011. v.1.

FARIAS, Cristiano Chaves de; ROSENVALD, Nelson. Curso de Direito Civil. $4^{\text {a }}$ Ed. Rio de Janeiro: Lumenjuris. 2010. v. 2.

FARIAS, Cristiano Chaves de; ROSENVALD, Nelson. Curso de Direito Civil. $9^{\text {a }}$ Ed. Rio de Janeiro: Lumenjuris. 2011. v. 1.

FURCK, Christiane Hessler. Conceito legal indeterminado: a função social do contrato e a função criadora do juiz. - Revista de Direito Privado, São Paulo, v. 09, n. 34, p. 85 a 104, abril 2008.

GAGLIANO, Pablo Stolze; FILHO, Rodolfo Pamplona. Novo curso de Direito Civil. 12 Ed. São Paulo: Saraiva. 2010. v. 1.

GOMES, Luiz Roldão de Freitas. Novos contratos e o atual Código Civil. Rio de Janeiro: Renovar. 2003.

GONÇALVES, Carlos Roberto. Direito Civil brasileiro. $3^{\text {a }}$ Ed. São Paulo: Saraiva. 2006. v. 1.

HERKENHOFF, Jõao Baptista. Direitos humanos: a construção universal de uma utopia. São Paulo: Editora Santuário; 2010.

HOUAISS, Antônio. Dicionário Houaiss da Língua Portuguesa. Rio de Janeiro: Objetiva; 2004.

ITÁLIA. Código Civil (1942). Disponível em:

<http://www.jus.unitn.it/cardozo/obiter_dictum/codciv/codciv.htm>. Acesso em 19 de maio de 2013.

MENDES, Gilmar Ferreira e COELHO; Inocêncio Martins e BRANCO; Paulo Gustavo Gonet. Curso de Direito Constitucional. $5^{\text {a }}$ ed. São Paulo: Saraiva; 2010.

MONTEIRO, Washington de Barros. Curso de Direito Civi. $40^{\text {a }}$ Ed. São Paulo: Saraiva. 2005. v. 1. 
NADER, Paulo. Introdução ao estudo do Direito. 31 a Ed. Rio de Janeiro: Forense. 2009.

ONU. Declaração Universal dos Direitos Humanos; 1945.

PEZZIMENTI, Rocco. Fraternidade: o porquê de um eclipse. In: Baggio, Antônio Maria (org.). O princípio esquecido/1. São Paulo: Cidade Nova; 2008. Cap. 2, p.57-76.

PIZZOLATO, Filippo. A fraternidade no ordenamento jurídico italiano. In: Baggio, Antônio Maria (org.). O princípio esquecido/1. São Paulo: Cidade Nova; 2008. Cap. 5, p.111-126.

RATZINGER, Joseph. La fraternidad cristiana (Die christliche Brüderlichkeit). Madrid, Editorial Taurus (Traducción de Jesús Collado); 1962.

ROPELATO, Daniela. Notas sobre participação e fraternidade. In: Baggio, Antônio Maria (org.). O princípio esquecido/1. São Paulo: Cidade Nova; 2008. Cap. 4, p.85-110.

ROSENVALD, Nelson. Dignidade Humana e boa-fé no Código Civil. São Paulo: Saraiva; 2007.

SANTOS, Eduardo Sens dos. A função social do contrato: elementos para uma conceituação. Revista de Direito Privado, São Paulo, v. 04; n. 13, p. 99 a 111, março 2003.

SARLET, Ingo Wolfgang. Dignidade da Pessoa Humana e Direitos Fundamentais. Porto Alegre: Livraria do Advogado; 2004.

SCHMIDT, Mário Furley. Nova História Crítica, 5ª série. São Paulo: Nova Geração; 2001.

TAVARES, Diógenes de Brito. Por um reposicionamento da fraternidade no âmbito das teorias da justiça e da democracia: elementos para a construção de uma sociedade fraterna e solidária. Revista de Direito Constitucional e Intemacional, São Paulo, v. 19, n. 75, p.187250, abril/jun 2011.

THEODORO JUNIOR, Humberto. O contrato social e sua função. Rio de Janeiro: Forense; 2008.

VILAÇA. Wagner Felipe Macedo. Fraternidade - uma compreensão normativa (jurídica) deste conceito. 2013. Relatório final (Projeto de Pesquisa) -PROBIC/FAPEMIG - nº 6825. 